\title{
OPEN Left and right ventricular functions may be impaired in children diagnosed with subclinical hypothyroidism
}

\author{
Alper Akın ${ }^{1 凶}$, Edip Unal ${ }^{2}$, Ruken Yildirim², Mehmet Ture ${ }^{1}$, Hasan Balik ${ }^{1}$ \& \\ Yusuf Kenan Haspolat ${ }^{2}$
}

Subclinical hypothyroidism (SH) may influence both ventricular functions. The aim of this study was to evaluation the findings of Tissue Doppler Imaging (TDI) and other echocardiography modalities in children with SH. We compared left ventricular mass index (LVMI) and TDI parameters of patients with $\mathrm{SH}$ and children with euthyroidism. Subclinical hypothyroidism was diagnosed when thyroid stimulating hormone level was higher than the reference value of the laboratory $(>4.2 \mathrm{mIU} / \mathrm{L})$ and free thyroxine level was in normal range. The study included a group of 35 patients with $\mathrm{SH}$ and a control group of 38 children with euthyroidism (mean age was $7.6 \pm 3.5$ years and $9.0 \pm 2.4$ years, respectively). LVMI was significantly higher in the patient group $(p=0.005)$. TDI parameters including mitral septal ejection time was lower $(p=0.003)$ and mitral septal myocardial performance index was higher $(p=0.009)$ in the patient group. Right ventricular TDI revealed that tricuspid lateral $E / E a$ and tricuspid septal $E / E a$ were higher $(p=0.015$ and $p=0.024$, respectively) and tricuspid septal Ea/Aa and ejection time were lower $(p=0.018$ and $p=0.017$, respectively) in the patient group. SH may lead to increase LVMI. Left ventricular systolic and diastolic TDI parameters (lower mitral septal ejection time, higher mitral septal myocardial performance index) as well as right ventricular systolic (lower tricuspid septal ejection time) and diastolic (higher tricuspid septal and lateral E/Ea, lower tricuspid septal Ea/ Ea) functions may be also impaired in children with subclinical hypothyroidism. TDI is a useful method used for the assessment of the effect of $\mathrm{SH}$ on cardiac functions.

Subclinical hypothyroidism is diagnosed when serum thyroid stimulating hormone level is increased and free thyroxine level is within normal reference ${ }^{1}$. Subclinical hypothyroidism has a prevalence of $3-18 \%$ of in adults ${ }^{2}$. Although, the prevalence of subclinical hypothyroidism in children remains unknown, it is reported that subclinical hypothyroidism is less frequent in children compared to adults ${ }^{3,4}$. Although numerous factors have been blamed in the etiology of subclinical hypothyroidism, autoimmune disorders of the thyroid gland are considered to be the most common cause of subclinical hypothyroidism both in children and adults 5 .

Most studies investing the effects of subclinical hypothyroidism have mostly been conducted in adults and there is a paucity of data regarding subclinical hypothyroidism in children. Subclinical hypothyroidism has been shown to influence the neuromuscular system, carbohydrate mechanism, and cognitive functions ${ }^{6-8}$. Nevertheless, subclinical hypothyroidism mainly attacks the cardiovascular system, mostly leading to left and right ventricular systolic and diastolic dysfunction, heart failure, coronary heart disease, vascular dysfunction with increased vascular stiffness and endothelial dysfunction, and increased left ventricular mass ${ }^{9-13}$.

Tissue Doppler imaging findings have been shown to be important in the subclinical hypothyroidism; however, most of these findings have been reported in adult studies ${ }^{10,14-16}$. The aim of this study was to compare the findings of Tissue Doppler Imaging and other echocardiography modalities (Two-dimensional and M-mode echocardiography) in children with subclinical hypothyroidism and control groups.

${ }^{1}$ Department of Pediatric Cardiology, Dicle University Faculty of Medicine, Sur, Diyarbakır, Turkey. ${ }^{2}$ Department of Pediatric Endocrinology, Dicle University Faculty of Medicine, Diyarbakır, Turkey. ${ }^{\square}$ email: alperakin1@ hotmail.com 


\section{Methods}

The study included 35 children diagnosed with subclinical hypothyroidism at Dicle University Medical School Department of Pediatric Endocrinology between September 2016 and February 2017 and 38 healthy euthyroid children with normal thyroid functions. Normal reference values of our laboratory where the study was conducted were as follows: thyroid stimulating hormone $0.27-4.2 \mathrm{mIU} / \mathrm{L}$, serum-free triiodothyronine 3.69-9.85 pmol/L, and free thyroxine 12-22.8 pmol/L. The diagnosis of subclinical hypothyroidism was established based on an increased thyroid stimulating hormone level (4.2-20 mIU/L) and normal serum-free triiodothyronine and free thyroxine levels measured in two morning fasting blood samples that were obtained at a minimum of a 15-day interval. Measurement of serum thyroid stimulating hormone, serum-free triiodothyronine and free thyroxine levels was performed by electrochemiluminescence immunoassay (ECLIA) method with a Cobos e601 analyzer (Roche HITACHI, Germany).

The children with SH were referred to pediatric endocrinology clinic by their physicians because of elevated serum TSH concentrations detected during check-up. No signs of hypertension, liver and kidney dysfunctions, lung disease, systemic infection, or chronic diseases were detected in any subject in both groups. Moreover, no subject was using medication during the study. The study excluded patients with obesity, low birth weight, diabetes mellitus, and a history of drug use. Electrocardiogram indicated normal sinus rhythm in all the subjects. In both groups' Transthoracic Echocardiographic examinations, the subjects that were detected with any pathology that could affect Tissue Doppler Imaging, such as valvular heart disease and congenital heart defect, were excluded from the study.

All the echocardiographic examinations were performed by an experienced pediatric cardiologist who was blinded to the clinical and biochemical characteristics of the patients. A written consent was received from the parents of each subject. The study was approved by the local ethics committee.

Transthorasic echocardiographic examinations was performed using a 2-4 MHz phased-array transducer (Vivid S5; GE, Horten, Norway). Transducers of 2.5 or $3.5 \mathrm{MHz}$ were used. Color flow and 2D Doppler echocardiography were performed at the apical four chamber, parasternal long axis, parasternal short axis, subcostal and at the suprasternal positions. M-mode echocardiography was performed at the parasternal long axis for the measurement of left ventricle end-diastolic diameter and left ventricle end-systolic diameter, fractional shortening, and ejection fraction. Left ventricle mass index was calculated by using the formula proposed by Devereux's et al. ${ }^{14}$. Using conventional Doppler transthoracic echocardiographic examinations, mitral and tricuspid early diastolic E wave $(\mathrm{m} / \mathrm{s})$, late diastolic A wave $(\mathrm{m} / \mathrm{s})$, and $\mathrm{E} / \mathrm{A}$ ratio were determined and evaluated in accordance with the American Society of Echocardiography guidelines ${ }^{17}$.

For the measurement of tissue Doppler, the pulse wave sample was positioned on the mitral lateral, mitral septal, tricuspid lateral and at the junction of the septal cusp of the tricuspid valve with the ventricle. For the measurement of interventricular septum, the pulse wave sample was placed parallel to the septum and was positioned at its upper $1 / 3$ part. Tissue Doppler Imaging was used to determine early diastolic velocity $\left(\mathrm{E}_{\mathrm{a}}, \mathrm{m} / \mathrm{s}\right)$, late diastolic velocity $\left(A_{a}, m / s\right)$, systolic velocity $\left(S_{a}, m / s\right)$, acceleration time $(\mathrm{ms})$, myocardial performance index, isovolumic contraction time (IVCT, ms), deceleration time (ms), ejection time (ejection time, ms) of the mitral valve, isovolumic relaxation time (IVRT, ms), tricuspid valve, and interventricular septum.

Statistics. Statistical analysis was performed by IBM SPSS 21.0 for Windows (SPSS Inc. Co., Chicago, IL, USA). Quantitative variables were expressed as mean \pm standard deviation (SD) and categorical variables as count and percentage (\%). Comparison of binary variables was performed by using independent samples $t$-test for normally distributed variables and Mann Whitney U test for non-normally distributed variables. Comparison of qualitative variables was performed by chi-square test. Pearson Correlation Coefficient was used for the analysis of the relationship among numerical variables. The hypotheses were two-tailed and a $p$ value of $\leq 0.05$ was considered significant.

Ethical approval. The authors assert that all procedures contributing to this study comply with the ethical standards of the relevant national guidelines on human experimentation and with the Helsinki Declaration of 1975, as revised in 2008, and has been approved by the institutional committees of Dicle University.

Informed consent. Informed consent was given by the participants or by their legal guardians.

Conference presentation. This study was presented at "52nd Annual Meeting of the Association for European Paediatric and Congenital Cardiology (in May 09-12, 2018, at Ahtens-Greece)” as a poster presentation.

\section{Results}

The study included a group of 35 (19 male, 16 female) patients with subclinical hypothyroidism and a control group of 38 healthy ( 20 male, 18 female) children with euthyroidism. Mean age was $7.6 \pm 3.5$ years in the patient group and $9.0 \pm 2.4$ years in the control group. No significant difference was found between the groups in terms of age, gender, body weight, and body mass index. Thyroid stimulating hormone was significantly higher $(p<0.001)$ and serum-free triiodothyronine and free thyroxine levels were similar compared to the control group. Of the 35 patients, 31 of them had a thyroid stimulating hormone of 5-10 mIU/L and 4 had a thyroid stimulating hormone of $\geq 10 \mathrm{mIU} / \mathrm{L}$. Table 1 presents the demographic and laboratory characteristics of the subjects in both groups.

Left ventricular mass index was significantly higher in the patient group compared to the control group $(p=0.005)$. However, left ventricle end-diastolic diameter, fractional shortening, and ejection fraction established no significant difference between the groups. Left ventricular end-systolic diameter was lower in the patient 


\begin{tabular}{|c|c|c|c|}
\hline & SH group $(n=35)$ & Control group $(n=38)$ & $p$ value \\
\hline Gender (female/male) & $19 / 16$ & $20 / 18$ & 0.887 \\
\hline Age (year) & $\begin{array}{l}7.6 \pm 3.5 \\
6.5(3.5-15.0)\end{array}$ & $\begin{array}{l}9.0 \pm 2.4 \\
8.7(4.5-15.0)\end{array}$ & 0.232 \\
\hline Weight (kg) & \begin{tabular}{|l|}
$25.4 \pm 11.8$ \\
$21.0(12.8-63.0)$
\end{tabular} & $\begin{array}{l}29.3 \pm 10.3 \\
27.7(16.0-57.0)\end{array}$ & 0.141 \\
\hline Height $(\mathrm{cm})$ & $121.2 \pm 19.44$ & $128.0 \pm 13.33$ & 0.076 \\
\hline BMI $\left(\mathrm{kg} / \mathrm{m}^{2}\right)$ & $\begin{array}{l}16.4 \pm 2.4 \\
15.7(13.7-25.0)\end{array}$ & $\begin{array}{l}16.6 \pm 2.8 \\
15.6(12.2-23.5)\end{array}$ & 0.899 \\
\hline Systolic blood pressure $(\mathrm{mmHg})$ & $104.5 \pm 5.5$ & $106.3 \pm 6.7$ & 0.241 \\
\hline Diastolic blood pressure $(\mathrm{mmHg})$ & $63.3 \pm 5.6$ & $65.8 \pm 7.6$ & 0.150 \\
\hline Heart rate (beats a minute) & $92.0 \pm 16.4$ & $87.0 \pm 15.1$ & 0.182 \\
\hline $\mathrm{TSH}(\mathrm{mIU} / \mathrm{L})$ & $\begin{array}{l}7.5 \pm 2.3 \\
6.7(5.0-14.5)\end{array}$ & $\begin{array}{l}2.4 \pm 0.7 \\
2.3(1.1-3.9)\end{array}$ & $<0.001$ \\
\hline $\mathrm{fT} 4(\mathrm{pmol} / \mathrm{L})$ & $\begin{array}{l}16.2 \pm 1.8 \\
16.6(12.6-19.0)\end{array}$ & $\begin{array}{l}16.9 \pm 1.9 \\
16.4(13.2-21.4)\end{array}$ & 0.164 \\
\hline $\mathrm{fT} 3(\mathrm{pmol} / \mathrm{L})$ & $\begin{array}{l}6.6 \pm 0.6 \\
6.7(5.6-7.2)\end{array}$ & $\begin{array}{l}6.7 \pm 0.7 \\
6.6(4.6-8.7)\end{array}$ & 0.655 \\
\hline
\end{tabular}

Table 1. Demographic and laboratory characteristic of the study groups. Data are given as mean \pm SD, and median (range). BMI body mass index, $f T 3$ free triiodothyronine, $f T 4$ free thyroxine, $S H$ subclinical hypothyroidism, TSH thyroid-stimulating hormone.

\begin{tabular}{|l|c|l|l|}
\hline & SH group $(\mathbf{n}=35)$ & Control group $(\mathbf{n}=38)$ & $p$ value \\
\hline LVEDd $(\mathrm{cm})$ & $3.4 \pm 0.5$ & $3.6 \pm 0.3$ & 0.139 \\
\hline LVESd $(\mathrm{cm})$ & $2.0 \pm 0.3$ & $2.2 \pm 0.2$ & 0.023 \\
\hline FS $(\%)$ & $39.8 \pm 4.2$ & $38.2 \pm 3.1$ & 0.088 \\
\hline EF $(\%)$ & $71.2 \pm 4.9$ & $69.5 \pm 3.7$ & 0.094 \\
\hline IVSd $(\mathrm{cm})$ & $0.6 \pm 0.1$ & $0.6 \pm 0.1$ & 0.160 \\
\hline PWd $(\mathrm{cm})$ & $0.6 \pm 0.11$ & $0.5 \pm 0.1$ & 0.105 \\
\hline LVMI $\left(\mathrm{g} / \mathrm{m}^{2}\right)$ & $68.1 \pm 19.8$ & $56.0 \pm 15.1$ & 0.005 \\
\hline
\end{tabular}

Table 2. M-Mode echocardiographic measurements of the study groups. Data are given as mean \pm SD. EF ejection fraction, $F S$ fractional shortening, IVSd thickness of the interventricular septum, $L V M I$ left ventricle mass index, $L V E D d$ left ventricle end-diastolic diameter, $L V E S d$ left ventricle end-systolic diameter, $P W d$ thickness of the left ventricle posterior wall, $\mathrm{SH}$ subclinical hypothyroidism.

group compared to the control group $(p=0.023)$. Table 2 presents M-Mode echocardiographic measurements of the two groups.

Mitral flow E wave velocity was significantly higher in the patient group compared to the control group $(p=0.020)$. Table 3 present the pulse-wave Doppler measurements of the two groups.

The comparison of Tissue Doppler Imaging parameters between the two groups indicated that mitral septal ejection time and deceleration time were lower ( $p=0.003$ and $p=0.040$, respectively) and myocardial performance index was higher $(p=0.009)$ in the patient group compared to the control group. Evaluation of the right ventricular Tissue Doppler Imaging revealed that tricuspid lateral $\mathrm{E} / \mathrm{E}_{\mathrm{a}}$ and tricuspid septal $\mathrm{E} / \mathrm{E}_{\mathrm{a}}$ were higher ( $p=0.015$ and $p=0.024$, respectively) and tricuspid septal $\mathrm{E}_{\mathrm{a}} / \mathrm{A}_{\mathrm{a}}$ and ejection time were lower $(p=0.018$ and $p=0.017$, respectively) in the patient group compared to the control group. Intraventricular septal $A_{a}$ was higher $(p=0.022)$ and $\mathrm{E}_{\mathrm{a}} / \mathrm{A}_{\mathrm{a}}$ was lower $(p=0.032)$ in the patient group compared to the control group. Table 4 presents the Tissue Doppler Imaging parameters of both groups.

Serum thyroid stimulating hormone level established a correlation with two parameters; a positive correlation was established with mitral septal $\mathrm{Aa}(\mathrm{r}=+0.380, \mathrm{p}=0.024)$ and a negative correlation was established with mitral flow ejection time $(\mathrm{r}=-0.456, \mathrm{p}=0.006)$.

\section{Discussion}

Myocardial tissue is highly sensitive to thyroid hormones due to its excess of thyroid hormone receptors ${ }^{18}$. Hypothyroidism could trigger cardiac remodeling in 3 manners. First, hypothyroidism reduces activity of several enzymes involved in intracellular calcium handling, thereby leading to alteration in the expression of contractile protein. Second, cardiac dysfunction may be caused by the chronic inflammation and tissue changes induced by subclinical hypothyroidism. Third, subclinical hypothyroidism is responsible for the hemodynamic alterations associated with cardiac impairment ${ }^{18-20}$. As a result of these, hypothyroidism leads to numerous changes in cardiac contractile, myocardial oxygen use, stroke volume, blood pressure, and systemic vascular resistance ${ }^{21}$. The effects of subclinical hypothyroidism on cardiac functions and Tissue Doppler Imaging parameters have 


\begin{tabular}{|l|c|c|l|}
\hline \multicolumn{2}{|l|}{$\begin{array}{l}\text { SH group (n=35) } \\
{[\text { mean }( \pm \text { SD) }]}\end{array}$} & $\begin{array}{l}\text { Control group (n=38) } \\
{[\text { mean }( \pm \text { SD) }}\end{array}$ & p value \\
\hline Left ventricle & $0.88 \pm 0.14$ & $0.81 \pm 0.11$ & 0.020 \\
\hline Mitral E velocity (m/s) & $0.54 \pm 0.11$ & $0.52 \pm 0.10$ & 0.405 \\
\hline Mitral A velocity (m/s) & $1.63 \pm 0.25$ & $1.55 \pm 0.25$ & 0.171 \\
\hline Mitral E/A & $77.83 \pm 14.95$ & $84.58 \pm 13.21$ & 0.044 \\
\hline AT (ms) & $94.29 \pm 25.17$ & $103.24 \pm 16.64$ & 0.075 \\
\hline DT (ms) & $285.14 \pm 46.26$ & $286.89 \pm 41.13$ & 0.865 \\
\hline ET (ms) & & & \\
\hline Right ventricle & $0.72 \pm 0.11$ & $0.69 \pm 0.12$ & 0.312 \\
\hline Tricuspid E velocity (m/s) & $0.52 \pm 0.11$ & $0.49 \pm 0.11$ & 0.360 \\
\hline Tricuspid A velocity (m/s) & $1.42 \pm 0.23$ & $1.39 \pm 0.19$ & 0.579 \\
\hline Tricuspid E/A & $92.83 \pm 23.24$ & $91.79 \pm 19.46$ & 0.836 \\
\hline AT (ms) & $108.43 \pm 26.85$ & $119.76 \pm 28.76$ & 0.087 \\
\hline DT (ms) & $278.00 \pm 53.52$ & $278.24 \pm 45.54$ & 0.984 \\
\hline ET (ms) & & & \\
\hline
\end{tabular}

Table 3. Pulse-wave Doppler measurements of the study groups. Data are given as mean $\pm \mathrm{SD}$. AT acceleration time, $D T$ deceleration time, ET ejection time, mitral A late transmitral flow velocity, mitral $E$ early transmitral flow velocity, tricuspid $A$ late transtricuspid flow velocity, tricuspid $E$ early transtricuspid flow velocity, $\mathrm{SH}$ subclinical hypothyroidism.

mostly been reported in adult studies ${ }^{10,11,15,16,18,22-24}$. Although the number of studies reporting on the cardiac effects of subclinical hypothyroidism have been growing recently, particularly in children, there is still scarcity in the number of studies conducted in children ${ }^{9,25}$.

Left ventricle mass has been shown to increase in adults with subclinical hypothyroidism ${ }^{11,18}$. Rodonti et al. ${ }^{12}$ reported that left ventricular mass might increase in patients with thyroid stimulating hormone $>10 \mathrm{mU} / \mathrm{l}$ during long-term follow-up although no increase might be seen at baseline measurements. A review of the Englishlanguage literature showed that there have been only two studies reporting on increased left ventricular mass in children with subclinical hypothyroidism ${ }^{9,26}$. Of these, the study by Catli et al. ${ }^{9}$ evaluated 31 children with subclinical hypothyroidism and found a significant increase in left ventricular mass index and interventricular septal thickness. The other study was conducted by Sert et al. ${ }^{26}$ which evaluated obese children with subclinical hypothyroidism and found increased left ventricular mass index in children with thyroid stimulating hormone $>4$ $\mathrm{mIU} / \mathrm{L}$ compared to children with thyroid stimulating hormone $<4 \mathrm{mIU} / \mathrm{L}$. Therefore, the present study is of prime value since it is one of the few studies in the literature showing that left ventricular mass index significantly increases in children with subclinical hypothyroidism.

Studies investigating mitral and tricuspid flow pulsed-wave Doppler have indicated that diastolic dysfunction may develop in children with subclinical hypothyroidism. Irdem et al. ${ }^{25}$ found that mitral E-wave velocity and E/A ratio were lower and mitral A-wave and IVRT were higher in children with subclinical hypothyroidism compared to healthy controls. Another study showed that no differences were found in mitral flow diastolic parameters (mitral flow E velocity, A velocity, E/A ratio, and deceleration time) between patients with subclinical hypothyroidism and healthy controls 9 . Some adult studies have also indicated that left ventricular systolic, in particular, and diastolic dysfunction may occur in patients with subclinical hypothyroidism ${ }^{15,22-24}$. In our study, mitral flow E velocity was higher in children with subclinical hypothyroidism compared to healthy controls, which contradicted with the findings of other studies that found lower mitral flow E velocity in children with subclinical hypothyroidism compared to controls ${ }^{9,25}$. However, a previous study that evaluated adults with subclinical hypothyroidism reported that peak E velocity was markedly higher in patients with thyroid stimulating hormone $>10 \mathrm{mU} / \mathrm{L}$ and that this finding represented left atrial pressure and was also associated with heart failure in patients with thyroid stimulating hormone $>10 \mathrm{mU} / \mathrm{L}^{11}$.

Subclinical hypothyroidism has been commonly associated with Tissue Doppler Imaging in adult studies $^{10,16,18,23}$. However, this association has been scarcely reported in pediatric studies ${ }^{9,25}$. Catli et al. ${ }^{9}$ reported that subclinical hypothyroidism was associated with left ventricular diastolic (lower $\mathrm{E}_{\mathrm{m}}^{\prime}$, higher E/ $\mathrm{E}_{\mathrm{m}}^{\prime}$ ratio, longer IVRT) and systolic (lower IVCT) dysfunctions in children with subclinical hypothyroidism. In addition, the study also found that lateral mitral myocardial performance index was higher, systolic IVCT was higher and ejection time was lower, and diastolic IVRT and myocardial performance index were higher. In contrast, Irdem et al. ${ }^{25}$ revealed that left ventricular septal $E_{m}$ velocity and $E_{m} / A_{m}$ ratio were markedly decreased and $A_{m}$ velocity was markedly increased in children with subclinical hypothyroidism compared to healthy controls. The authors also reported that left ventricular lateral $E_{m}$ velocity and $E_{m} / A_{m}$ ratio were lower and $E / E_{m}$ ratio was higher in the patient group.

Myocardial performance index is a simple method used in the evaluation of systolic and diastolic cardiac functions. Moreover, increased myocardial performance index is an indicator of impaired systolic and diastolic functions ${ }^{27}$. In the present study, increased mitral septal myocardial performance index and ejection time indicated impaired diastolic and global ventricular function. Catli et al. ${ }^{9}$ found increased mitral lateral myocardial performance index in children with subclinical hypothyroidism, whereas we found increased mitral septal 


\begin{tabular}{|c|c|c|c|}
\hline & $\begin{array}{l}\text { SH group }(\text { n 35) } \\
{[\text { mean }( \pm \text { SD })]}\end{array}$ & $\begin{array}{l}\text { Control group (n 38) } \\
{[\text { mean }( \pm \text { SD })]}\end{array}$ & p value \\
\hline \multicolumn{4}{|c|}{ Mitral lateral } \\
\hline $\mathrm{S}_{\mathrm{a}}(\mathrm{m} / \mathrm{s})$ & $0.05 \pm 0.01$ & $0.05 \pm 0.01$ & 0.835 \\
\hline $\mathrm{E}_{\mathrm{a}}(\mathrm{m} / \mathrm{s})$ & $0.11 \pm 0.02$ & $0.10 \pm 0.01$ & 0.280 \\
\hline $\mathrm{A}_{\mathrm{a}}(\mathrm{m} / \mathrm{s})$ & $0.07 \pm 0.02$ & $0.06 \pm 0.01$ & 0.252 \\
\hline $\mathrm{Ea} / \mathrm{A}_{\mathrm{a}}$ & $1.68 \pm 0.28$ & $1.68 \pm 0.23$ & 0.915 \\
\hline IVRT (ms) & $65.11 \pm 17.53$ & $64.53 \pm 12.18$ & 0.867 \\
\hline IVCT (ms) & $58.26 \pm 13.71$ & $60.63 \pm 12.43$ & 0.440 \\
\hline ET (ms) & $234.06 \pm 25.42$ & $244.95 \pm 30.63$ & 0.104 \\
\hline AT (ms) & $50.77 \pm 11.71$ & $51.50 \pm 11.47$ & 0.789 \\
\hline $\mathrm{DT}(\mathrm{ms})$ & $67.09 \pm 10.73$ & $71.00 \pm 13.37$ & 0.175 \\
\hline $\mathrm{E} / \mathrm{E}_{\mathrm{a}}$ & $8.01 \pm 2.16$ & $7.57 \pm 1.65$ & 0.331 \\
\hline MPI & $0.53 \pm 0.12$ & $0.52 \pm 0.10$ & 0.585 \\
\hline \multicolumn{4}{|c|}{\begin{tabular}{|l|} 
Mitral septal \\
\end{tabular}} \\
\hline $\mathrm{S}_{\mathrm{a}}(\mathrm{m} / \mathrm{s})$ & $0.07 \pm 0.01$ & $0.06 \pm 0.01$ & 0.349 \\
\hline$E_{a}(m / s)$ & $0.11 \pm 0.01$ & $0.11 \pm 0.01$ & 0.430 \\
\hline $\mathrm{A}_{\mathrm{a}}(\mathrm{m} / \mathrm{s})$ & $0.07 \pm 0.02$ & $0.06 \pm 0.08$ & 0.071 \\
\hline $\mathrm{E}_{\mathrm{a}} / \mathrm{A}_{\mathrm{a}}$ & $1.59 \pm 0.30$ & $1.67 \pm 0.21$ & 0.210 \\
\hline IVRT (ms) & $62.51 \pm 17.45$ & $57.84 \pm 10.42$ & 0.175 \\
\hline IVCT (ms) & $53.86 \pm 11.40$ & $52.63 \pm 10.26$ & 0.632 \\
\hline ET (ms) & $239.26 \pm 24.89$ & $255.50 \pm 19.31$ & 0.003 \\
\hline AT (ms) & $47.97 \pm 8.83$ & $50.89 \pm 10.12$ & 0.195 \\
\hline DT (ms) & $69.94 \pm 16.30$ & $78.39 \pm 18.10$ & 0.040 \\
\hline $\mathrm{E} / \mathrm{A}_{\mathrm{a}}$ & $7.57 \pm 1.57$ & $7.10 \pm 1.06$ & 0.147 \\
\hline MPI & $0.49 \pm 0.11$ & $0.43 \pm 0.06$ & 0.009 \\
\hline \multicolumn{4}{|c|}{ Tricuspid lateral } \\
\hline $\mathrm{S}_{\mathrm{a}}(\mathrm{m} / \mathrm{s})$ & $0.11 \pm 0.02$ & $0.11 \pm 0.01$ & 0.582 \\
\hline $\mathrm{E}_{\mathrm{a}}(\mathrm{m} / \mathrm{s})$ & $0.15 \pm 0.02$ & $0.15 \pm 0.02$ & 0.242 \\
\hline $\mathrm{A}_{\mathrm{a}}(\mathrm{m} / \mathrm{s})$ & $0.11 \pm 0.03$ & $0.11 \pm 0.02$ & 0.574 \\
\hline $\mathrm{E}_{\mathrm{a}} / \mathrm{A}_{\mathrm{a}}$ & $1.40 \pm 0.30$ & $1.49 \pm 0.26$ & 0.202 \\
\hline IVRT (ms) & $60.43 \pm 10.02$ & $57.32 \pm 11.41$ & 0.339 \\
\hline IVCT (ms) & $60.77 \pm 14.60$ & $59.11 \pm 11.25$ & 0.585 \\
\hline ET (ms) & $246.43 \pm 35.33$ & $249.71 \pm 23.12$ & 0.643 \\
\hline AT (ms) & $65.69 \pm 15.86$ & $70.87 \pm 16.41$ & 0.135 \\
\hline DT (ms) & $82.74 \pm 22.45$ & $91.71 \pm 21.09$ & 0.083 \\
\hline $\mathrm{E} / \mathrm{E}_{\mathrm{a}}$ & $4.92 \pm 0.97$ & $4.40 \pm 0.80$ & 0.015 \\
\hline MPI & $0.50 \pm 0.13$ & $0.46 \pm 0.08$ & 0.154 \\
\hline \multicolumn{4}{|c|}{ Tricuspid septal } \\
\hline $\mathrm{S}_{\mathrm{a}}(\mathrm{m} / \mathrm{s})$ & $0.08 \pm 0.01$ & $0.07 \pm 0.01$ & 0.262 \\
\hline $\mathrm{E}_{\mathrm{a}}(\mathrm{m} / \mathrm{s})$ & $0.11 \pm 0.02$ & $0.12 \pm 0.01$ & 0.245 \\
\hline $\mathrm{A}_{\mathrm{a}}(\mathrm{m} / \mathrm{s})$ & $0.08 \pm 0.02$ & $0.07 \pm 0.02$ & 0.520 \\
\hline $\mathrm{E}_{\mathrm{a}} / \mathrm{A}_{\mathrm{a}}$ & $1.54 \pm 0.30$ & $1.69 \pm 0.24$ & 0.018 \\
\hline IVRT (ms) & $57.94 \pm 16.13$ & $55.55 \pm 8.97$ & 0.443 \\
\hline IVCT (ms) & $52.26 \pm 10.03$ & $53.68 \pm 10.01$ & 0.545 \\
\hline ET (ms) & $242.17 \pm 26.80$ & $255.42 \pm 19.37$ & 0.017 \\
\hline AT (ms) & $51.97 \pm 13.19$ & $54.50 \pm 6.96$ & 0.304 \\
\hline $\mathrm{DT}(\mathrm{ms})$ & $70.63 \pm 17.43$ & $75.53 \pm 12.36$ & 0.174 \\
\hline $\mathrm{E} / \mathrm{E}_{\mathrm{a}}$ & $6.30 \pm 1.18$ & $5.67 \pm 1.14$ & 0.024 \\
\hline MPI & $0.46 \pm 0.10$ & $0.43 \pm 0.05$ & 0.156 \\
\hline \multicolumn{4}{|c|}{ Interventricular septum } \\
\hline $\mathrm{S}_{\mathrm{a}}(\mathrm{m} / \mathrm{s})$ & $0.05 \pm 0.00$ & $0.05 \pm 0.01$ & 0.070 \\
\hline $\mathrm{E}_{\mathrm{a}}(\mathrm{m} / \mathrm{s})$ & $0.10 \pm 0.02$ & $0.10 \pm 0.01$ & 0.722 \\
\hline $\mathrm{A}_{\mathrm{a}}(\mathrm{m} / \mathrm{s})$ & $0.06 \pm 0.01$ & $0.05 \pm 0.00$ & 0.022 \\
\hline $\mathrm{E}_{\mathrm{a}} / \mathrm{A}_{\mathrm{a}}$ & $1.76 \pm 0.31$ & $1.90 \pm 0.23$ & 0.032 \\
\hline IVRT (ms) & $57.80 \pm 14.53$ & $57.68 \pm 13.32$ & 0.972 \\
\hline IVCT (ms) & $53.06 \pm 11.36$ & $55.13 \pm 9.58$ & 0.401 \\
\hline ET (ms) & $244.63 \pm 23.39$ & $251.26 \pm 18.88$ & 0.185 \\
\hline Continued & & & \\
\hline
\end{tabular}




\begin{tabular}{|l|c|l|l|}
\hline & $\begin{array}{l}\text { SH group }(\mathbf{n} 35) \\
{[\text { mean }( \pm \text { SD })]}\end{array}$ & $\begin{array}{l}\text { Control group }(\mathbf{n} 38) \\
{[\text { mean }( \pm \text { SD })]}\end{array}$ & p value \\
\hline AT $(\mathrm{ms})$ & $52.97 \pm 9.38$ & $56.00 \pm 9.13$ & 0.167 \\
\hline DT $(\mathrm{ms})$ & $55.54 \pm 8.46$ & $60.97 \pm 11.23$ & 0.023 \\
\hline MPI & $0.46 \pm 0.08$ & $0.44 \pm 0.07$ & 0.379 \\
\hline
\end{tabular}

Table 4. TDI parameters of the study groups. Data are given as mean $\pm \mathrm{SD}$. $A_{a}$ atrial diastolic wave, $A T$ acceleration time, $D T$ deceleration time, $E$ early transvalvular flow velocity, $E_{a}$ early diastolic wave, $E T$ ejection time, IVCT isovolumic contraction time, IVRT isovolumic relaxation time, MPI myocardial performance index, $S_{a}$ myocardial systolic wave, $S H$ subclinical hypothyroidism, TDI tissue Doppler imaging.

myocardial performance index. These two findings suggest that global ventricular function may be impaired in children with subclinical hypothyroidism.

Besides left ventricular functions, right ventricular functions may also be impaired in patients with subclinical hypothyroidism ${ }^{10,16,18}$. In our study, of the right ventricular Tissue Doppler Imaging diastolic parameters analyzed, tricuspid septal and lateral $\mathrm{E} / \mathrm{E}_{\mathrm{a}}$ ratio were higher in children with subclinical hypothyroidism compared to controls, which indicated right ventricular diastolic dysfunction (impaired ventricular filling). Catli et al. ${ }^{9}$ reported that mitral annulus $\mathrm{E} / \mathrm{A}_{\mathrm{a}}$ ratio was higher in children with subclinical hypothyroidism compared to controls; however, we found no study in the literature reporting on increased tricuspid annulus $E / A_{a}$ ratio in children with subclinical hypothyroidism. On the other hand, in our study, we found that tricuspid septal $E_{a} / A_{a}$ was lower in children with subclinical hypothyroidism compared to controls. A similar finding was reported by Kosar et al. ${ }^{16}$, who suggested that this finding was another indicator of right ventricular diastolic dysfunction. The same study also revealed that both mitral annular $\mathrm{E}_{\mathrm{a}} / \mathrm{A}_{\mathrm{a}}$ ratio and tricuspid annular $\mathrm{E}_{\mathrm{a}} / \mathrm{A}_{\mathrm{a}}$ ratio were lower and a negative correlation was found between thyroid stimulating hormone and $\mathrm{E}_{\mathrm{a}}$ velocity and $\mathrm{E}_{\mathrm{a}} / \mathrm{A}_{\mathrm{a}}$ ratio. The findings reported by Kosar et al. ${ }^{16}$ suggest that not only left ventricular diastolic functions but also right ventricular diastolic functions may be impaired in patients with subclinical hypothyroidism. Similarly, we also found that tricuspid septal ejection time was lower in children with subclinical hypothyroidism compared to controls, which indicated impairment in right ventricular systolic functions. In this regard, our study is the first study in the literature showing that left ventricular dysfunction as well as right ventricular systolic and diastolic dysfunction may occur in children with subclinical hypothyroidism.

Increased $\mathrm{A}_{\mathrm{a}}$ wave and decreased $\mathrm{E}_{\mathrm{a}} / \mathrm{A}_{\mathrm{a}}$ ratio at interventricular septum may indicate impaired global ventricular diastolic functions. Catli et al. ${ }^{9}$ also investigated interventricular septum Tissue Doppler Imaging and suggested that systolic (higher IVCT, lower ejection time), diastolic (higher IVRT), and global (higher myocardial performance index) functions may be impaired in children with subclinical hypothyroidism.

There are adult studies showing that some myocardial dysfunction indicators measured by Tissue Doppler Imaging and conventional echocardiography have significant correlations with serum thyroid stimulating hormone levels in subclinical hypothyroidism ${ }^{10,18}$. Our study revealed that as thyroid stimulating hormone level increases, mitral flow ejection time decreases (related to left ventricular systolic dysfunction) and mitral septal Aa increases (related to left ventricular diastolic dysfunction). This correlation indicates the importance of the effect of increased thyroid stimulating hormone level on the development of left ventricular systolic and diastolic dysfunction in children with subclinical hypothyroidism. To our knowledge, this correlation has never been reported in any study in the literature. In our study, thyroid stimulating hormone levels were significantly different between the subclinical hypothyroidism and the control group; however, sT4 and sT3 levels were similar, and no significant correlation was found between sT4 and sT3 levels and myocardial dysfunction indicators as in TSH. For these reasons, we think that the main cause of myocardial dysfunction is thyroid stimulating hormone.

\section{Conclusion}

Subclinical hypothyroidism may lead to increased left ventricular mass index. Our study is one of the few studies in the literature showing that left ventricular mass index may be increased in children with subclinical hypothyroidism. Although the present study showed that increased left ventricular mass index may have adverse effects on ventricular functions in children with subclinical hypothyroidism, further studies with longer periods are needed to investigate these effects. Our study also indicated that left ventricular systolic and diastolic Tissue Doppler Imaging parameters (lower mitral septal ejection time, higher mitral septal myocardial performance index) as well as right ventricular systolic (lower tricuspid septal ejection time) and diastolic (higher tricuspid septal and lateral $E / E_{a}$, lower tricuspid septal $E_{a} / E_{a}$ ) functions may be impaired in children with subclinical hypothyroidism. Although left and right ventricular dysfunctions have been commonly reported in adults with subclinical hypothyroidism in echocardiographic studies, our study is the first study in the literature showing that left ventricular dysfunction as well as right ventricular systolic and diastolic dysfunction may occur in children with subclinical hypothyroidism.

Study limitations. This study has several limitations. Firstly, the study evaluates cardiac functions in children with SH. However, long-term follow-up of patients and cardiac functions have not been performed. For this reason, longer-term studies are needed. The small number of patients may also act as another limitation of our study. 
Received: 23 August 2019; Accepted: 27 July 2020

Published online: 12 November 2020

\section{References}

1. Çatlı, G., Abacı, A., Büyükgebiz, A. \& Bober, E. Subclinical hypothyroidism in childhood and adolescence. J. Pediatr. Endocr. Met. 27, 1049-1057 (2014).

2. Baumgartner, C., Blum, M. R. \& Rodondi, N. Subclinical hypothyroidism: Summary of evidence in 2014. Swiss. Med. Wkly. 144, w14058 (2014).

3. Gawlik, A. et al. Subclinical hypothyroidism in children and adolescents: Is it clinically relevant?. Int. J. Endocrinol. 2015, 69107 (2015).

4. Biondi, B., Palmieri, E. A., Lombardi, G. \& Fazio, S. Subclinical hypothyroidism and cardiac function. Thyroid. 12, 505-510 (2002).

5. Biondi, B. Natural history, diagnosis and management of subclinical thyroid dysfunction. Best Pract. Res. Clin. Endocrinol. Metab. 26, 431-446 (2012).

6. Meier, C. et al. TSH-controlled L-thyroxine therapy reduces cholesterol levels and clinical symptoms in subclinical hypothyroidism: A double blind, placebo-controlled trial (Basel Thyroid Study). J. Clin. Endocrinol. Metab. 86, 4860-4866 (2001).

7. Arikan, S., Bahceci, M., Tuzcu, A., Çelik, F. \& Gökalp, D. Postprandial hyperlipidemia in overt and subclinical hypothyroidism. Eur. J. Intern. Med. 23, e141-145 (2012).

8. Ergur, A. T. et al. Neurocognitive functions in children and adolescents with subclinical hypothyroidism. J. Clin. Res. Pediatr. Endocrinol. 4, 21-24 (2012).

9. Catli, G. et al. The effect of L-thyroxine treatment on left ventricular functions in children with subclinical hypothyroidism. Arch. Dis. Child. 100, 130-137 (2015).

10. Turhan, S. et al. Effects of thyroxine therapy on right ventricular systolic and diastolic function in patients with subclinical hypothyroidism: A study by pulsed wave tissue doppler imaging. J. Clin. Endocrinol. Metab. 91, 3490-3493 (2006).

11. Gill, P. S. et al. Subclinical thyroid dysfunction and cardiac function amongst minority ethnic groups in the UK: A cross sectional study. Int. J. Cardiol. 168, 5218-5220 (2013).

12. Rodondi, N. et al. Subclinical hypothyroidism and the risk of coronary heart disease and mortality. JAMA 304, 1365-1374 (2010).

13. Razvi, S., Ingoe, L., Keeka, G., Oates, C. \& Weaver, J. U. The beneficial effect of L-thyroxine on cardiovascular risk factors, endothelial function, and quality of life in subclinical hypothyroidism: randomized, crossover trial. J. Clin. Endocrinol. Metab. 92, 1715$1723(2007)$.

14. Chen, X., Zhang, N., Cai, Y. \& Shi, J. Evaluation of left ventricular diastolic function using tissue Doppler echocardiography and conventional doppler echocardiography in patients with subclinical hypothyroidism aged <60 years: A meta-analysis. J. Cardiol. 61, 8-15 (2013).

15. Yazici, M. et al. Effects of thyroxin therapy on cardiac function in patients with subclinical hypothyroidism: Index of myocardial performance in the evaluation of left ventricular function. Int. J. Cardiol. 95, 135-143 (2004).

16. Koşar, F. et al. Evaluation of right and left ventricular function using pulsed-wave tissue Doppler echocardiography in patients with subclinical hypothyroidism. J. Endocrinol. Invest. 28, 704-710 (2005).

17. Quinones, M. A., Otto, C. M., Stoddard, M., Waggoner, A. \& Zoghbi, W. A. Recommendations for quantification of Doppler echocardiography: A report from the Doppler Quantification Task Force of the Nomenclature and Standards Committee of the American Society of Echocardiography. J. Am. Soc. Echocardiogr. 15, 167-184 (2002).

18. Ilic, S. et al. Left and right ventricular structure and function in subclinical hypothyroidism: The effects of one-year levothyroxine treatment. Med. Sci. Monit. 19, 960-968 (2013).

19. Biondi, B., Palmieri, E. A., Lombardi, G. \& Fazio, S. Effects of thyroid hormone on cardiac function: The relative importance of heart rate, loading conditions, and myocardial contractility in the regulation of cardiac performance in human hyperthyroidism. J. Clin. Endocrinol. Metab. 87, 968-974 (2002).

20. Aksoy, D. Y. et al. Serum resistin and high sensitive CRP levels in patients with subclinical hypothyroidism before and after L-thyroxine therapy. Med. Sci. Monit. 19, 210-215 (2013).

21. Klein, I. \& Ojamaa, K. Thyroid hormone and the cardiovascular system. N. Engl. J. Med. 344, 501-509 (2001).

22. Biondi, B. et al. Left ventricular diastolic dysfunction in patients with subclinical hypothyroidism. J. Clin. Endocrinol. Metab. 84, 2064-2067 (1999).

23. Oner, F. A., Yurdakul, S., Oner, E., Uzum, A. K. \& Erguney, M. Evaluation of the effect of L-thyroxine therapy on cardiac functions by using novel tissue Doppler-derived indices in patients with subclinical hypothyroidism. Acta Cardiol. 66, 47-55 (2011).

24. Shatynska-Mytsyk, I. et al. The impact of thyroid hormone replacement therapy on left ventricular diastolic function in patients with subclinical hypothyroidism. J. Endocrinol. Invest. 39, 709-713 (2016).

25. İrdem, A. et al. Evaluation of P-wave dispersion, diastolic function, and atrial electromechanical conduction in pediatric patients with subclinical hypothyroidism. Echocardiography. 33, 1397-1401 (2016).

26. Sert, A., Pirgon, O., Aypar, E., Yllmaz, H. \& Odabas, D. Subclinical hypothyroidism as a risk factor fort he development of cardiovascular disease in obese adolescent with nonalcholic fatty liver disease. Pediatr. Cardiol. 34, 1166-1174 (2013).

27. Tei, C. et al. New index of combined systolic and diastolic myocardial performance: A simple and reproducible measure of cardiac function study in normals and dilated cardiomyopathy. J. Cardiol. 26, 357-366 (1995).

\section{Author contributions}

A.A., E.U. and M.T. conceived the study. M.T., H.B., and R.Y. performed and analyzed the experiments. A.A. and E.U. wrote the original draft, M.T., H.B., and Y.K.H. reviewed and edited and all authors read and approved the final manuscript.

\section{Funding}

This research received no specific grant from any funding agency or from commercial or not-for-profit sectors.

\section{Competing interests}

The authors declare no competing interests.

\section{Additional information}

Correspondence and requests for materials should be addressed to A.A.

Reprints and permissions information is available at www.nature.com/reprints. 
Publisher's note Springer Nature remains neutral with regard to jurisdictional claims in published maps and institutional affiliations.

(c) (i) Open Access This article is licensed under a Creative Commons Attribution 4.0 International License, which permits use, sharing, adaptation, distribution and reproduction in any medium or format, as long as you give appropriate credit to the original author(s) and the source, provide a link to the Creative Commons licence, and indicate if changes were made. The images or other third party material in this article are included in the article's Creative Commons licence, unless indicated otherwise in a credit line to the material. If material is not included in the article's Creative Commons licence and your intended use is not permitted by statutory regulation or exceeds the permitted use, you will need to obtain permission directly from the copyright holder. To view a copy of this licence, visit http://creativecommons.org/licenses/by/4.0/.

(c) The Author(s) 2020 